\title{
Design and Analysis of a Permanent-Magnet-Assisted Switched Reluctance Motor
}

\author{
Hongsik Hwang*, Jin Hur** and Cheewoo Lee ${ }^{\dagger}$
}

\begin{abstract}
A permanent-magnet-assisted switched reluctance motor (SRM) having small excitation poles, where phase coils are concentrically wound on the poles and thin permanent magnets are inserted inside the poles, is proposed in this paper. The insertion of permanent magnets into the stator excitation poles has a significant influence on positive torque improvement leading to a boost in efficiency. Three key design parameters such as the thickness of permanent magnets, space between two adjacent permanent magnets, and the width of stator excitation poles are determined during a design procedure in terms of the enhancement of positive torque. Step-by-step design modification and a comparison between the proposed permanent-magnet-assisted SRM and no-permanent-magnet SRM have been conducted by means of static torque comparison along with dynamic performance. The first prototype from steel laminations up to its physical assembly has been constructed.
\end{abstract}

Keywords: Brushless motor, Switched reluctance motor, Permanent-magnet assistance

\section{Introduction}

Brushless motors such as brushless DC motors (BLDCMs) and switched reluctance motors (SRMs) have been gaining significant attention in many applications [1-2], and a BLDCM is more effective in high power density and high efficiency. However, placing permanent magnets in the rotor of the BLDCM makes this motor suffer from the possibility of irreversible demagnetization by high temperature or armature reaction flux. Also, the mechanical integrity of permanent magnets inside the rotor gives this motor a limit in high-speed applications. On the other hand, the absence of permanent magnets in SRMs leads to cost effectiveness as a merit but offers lower efficiency and lower power density as a demerit at the same time compared to BLDCMs [3]. Recent cost rise in rare earth permanent magnet materials intensifies a need for the combination of an SRM with a BLDCM by slightly adding permanent magnets into the stator of the SRM such as doubly-salient permanent magnet machine [4], flux-reversal permanent magnet machine [5] and flux-switching permanent magnet machine [6].

In this paper, a permanent-magnet-assisted switched reluctance motor having small excitation poles, where phase coils are concentrically wound on the poles and thin permanent magnets are inserted inside the poles, is proposed. A step-by-step design procedure has been analytically conducted and also the benefit of the proposed

$\dagger \quad$ Corresponding Author: Dept. of Electrical and Computer Engineering, Pusan National University, South Korea. (cwlee1014@pusan.ac.kr)

* Dept. of Electrical and Computer Engineering, Pusan National University, South Korea.

** School of Electrical Engineering, University of Ulsan, South Korea. (jinhur@ulsan.ac.kr)

Received: May 12, 2014; Accepted: August 29, 2014 permanent-magnet-assisted structure has been verified by a comparison with no-permanent-magnet SRM in terms of static torque comparison along with dynamic performance. Additionally, the first prototype of the proposed permanentmagnet-assisted SRM has been built up, and its stator and rotor laminations including its physical assembly are given in this paper.

\section{Concept of Permanent-Magnet-Assisted SRM}

Table 1 gives physical information and key specification for the proposed permanent-magnet-assisted SRM in the paper, and the outer diameter and stack length of the machine are $121.52 \mathrm{~mm}$ and $70.0 \mathrm{~mm}$, respectively, along with 1.5 kilowatt at 3,000 revolutions per minute (rpm) as its rated condition.

Fig. 1 illustrates the effect of insertion of permanent magnets into the stator excitation poles of the proposed SRM in terms of positive flux combination with existing flux generated by the excitation poles compared to a conventional two-phase four-stator-pole two-rotor-pole (4/2) SRM.

Table 1. Information of permanent-magnet-assisted SRM

\begin{tabular}{c|c|c}
\hline & Unit & Value \\
\hline \hline Stator OD & $\mathrm{mm}$ & 121.52 \\
\hline Stack length & $\mathrm{mm}$ & 70.0 \\
\hline Air gap & $\mathrm{mm}$ & 0.5 \\
\hline Core material & - & $\mathrm{S} 18(\mathrm{t} 0.5 \mathrm{~mm})$ \\
\hline DC link voltage & $\mathrm{Vdc}$ & $300-310$ \\
\hline Rated output & $\mathrm{kW}$ & 1.5 \\
\hline Rated speed & $\mathrm{rpm}$ & 3,000 \\
\hline Rated torque & $\mathrm{Nm}$ & 4.65 \\
\hline
\end{tabular}




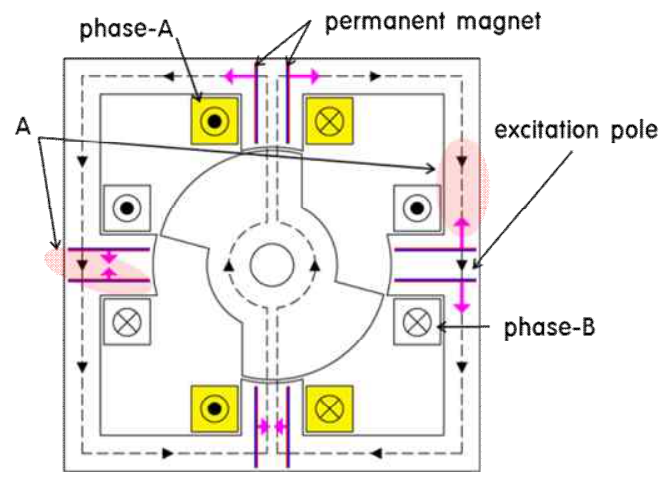

(a)

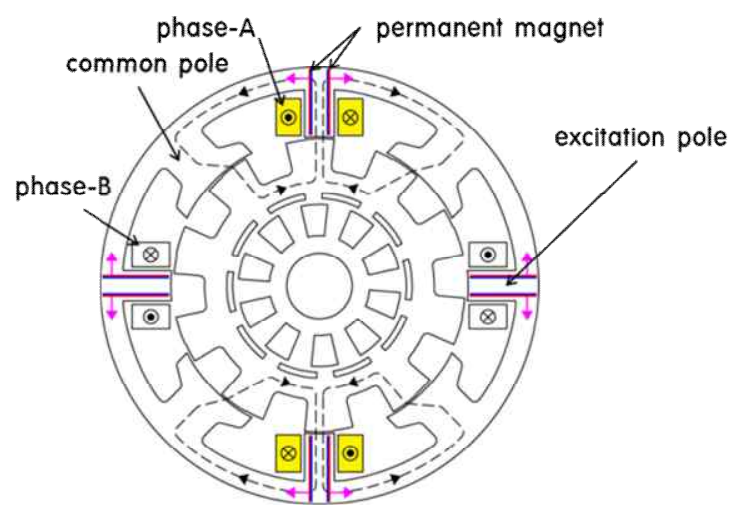

(b)

Fig. 1. Comparison of two SRMs in terms of placing permanent magnets during phase-A excitation: (a) conventional two-phase 4/2 SRM; (b) proposed two-phase 8/10 SRM

As shown in Fig. 1(a), two thin permanent magnets have been inserted into every stator pole in such a way that the permanent magnets are magnetized according to the polarity of windings in each stator pole. During phase-A excitation in windings, the four corresponding permanent magnets are sure to match their coils regarding the direction of flux. In this case, however, flux cancellation happens partly in the other phase as shaded in the figure (position " $A$ ") between the energized windings and permanent magnets of phase-B due to the share of stator back iron as a flux path in the two-phase 4/2 SRM. Like the 4/2 SRM, the conflict of coils' flux with permanent magnets' flux gives a conventional SRM a big bottleneck in increasing its power density by employing permanent magnets into the magnetic structure.

As shown in Fig. 1(b), the two-phase 8/10 SRM has two thin permanent magnets in each stator excitation pole in the same manner as the 4/2 SRM, and four dashed loops in Fig. 1(b) are denoted as a flux path when the two phases are excited independently. It is obvious that four permanent magnets buried in the stator poles of phase-A have to generate magnetic fields in the identical direction of coils of the same phase, but the flux paths are separated from those of the other phase unlike the 4/2 SRM. The independent production of flux between phases are allowed this proposed magnetic structure to boost power density by means of the addition of permanent magnets inside its stator excitation poles since there is no cancellation in flux at all. It is noted that permanent magnets in the $8 / 10$ magnetic configuration should assist windings' flux.

\section{Design and Analysis of Permanent-Magnet- Assisted SRM}

\subsection{Placement of permanent magnets in terms of torque performance}

In order to investigate the effect of permanent magnets' placement on static torque in the permanent-magnetassisted SRM, two key design factors are chosen as space between two adjacent permanent magnets $\left(w_{a}\right)$ and the thickness of each permanent magnet $\left(w_{b}\right)$, respectively. Table 2 gives the variation of the design parameters, and the space $\left(w_{a}\right)$ is ranged from $2.0 \mathrm{~mm}$ to $4.0 \mathrm{~mm}$ in $0.4 \mathrm{~mm}$ increments without the change of the thickness $\left(w_{b}\right)$ as fixed in $1.0 \mathrm{~mm}$.

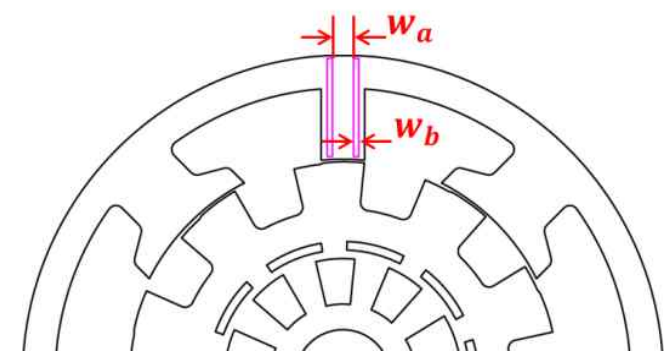

Fig. 2. Two design parameters as space between permanent magnets $\left(w_{a}\right)$ and thickness $\left(w_{b}\right)$

Table 2. Change of two design parameters regarding permanent magnets

\begin{tabular}{l|l|l|l|l|l|l|l}
\hline$w_{a}$ & $\mathrm{~mm}$ & 2.0 & 2.4 & 2.8 & 3.2 & 3.6 & 4.0 \\
\hline$w_{b}$ & $\mathrm{~mm}$ & \multicolumn{7}{|c}{1.0} \\
\hline
\end{tabular}

The average static torque of the $8 / 10$ permanent-magnetassisted SRM is examined by varying space between two adjacent permanent magnets $\left(w_{a}\right)$ ranging from $2.0 \mathrm{~mm}$ up to $4.0 \mathrm{~mm}$ when torque in the case of no permanent magnets is considered as a base, and the result of average static torque at $2 \mathrm{~A}$ is given in Fig. 3. It is shown that average static torque goes up gradually compared to the no-permanent-magnet case since the reluctance of excitation poles becomes lower as the space increases, and the average torque of the permanent-magnet-assisted SRM is $432.9 \%$ and $941.6 \%$ in the space of $2.0 \mathrm{~mm}$ and $4.0 \mathrm{~mm}$, respectively, compared to the magnetic structure of no permanent magnets as shown in Fig. 3. 


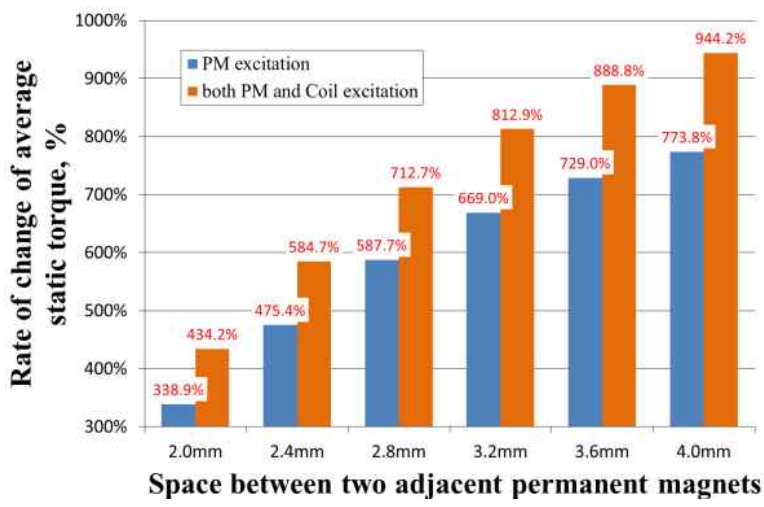

Fig. 3. Average static torque at $2 \mathrm{~A}$ in the permanentmagnet-assisted SRM compared to the case of no permanent magnets by varying space between permanent magnets $\left(w_{a}\right)$

\subsection{Torque performance with saturation}

As noticed just before, the average torque of the $8 / 10$ permanent-magnet-assisted SRM is higher than that of nopermanent-magnet design regardless of space between two adjacent permanent magnets $\left(w_{a}\right)$. However, this study has been done at $2 \mathrm{~A}$ which is recognized as low saturation based on the rated condition of 1.5 kilowatt at 3,000 rpm, and hence, the examination of torque of the proposed $8 / 10$ SRM is stretched to magnetically saturated position ranging from $2 \mathrm{~A}$ up to $20 \mathrm{~A}$. Fig. 4 shows the change of torque in the permanent-magnet-assisted SRM having $4.0 \mathrm{~mm}$ in $w_{a}$ compared to the case of no permanent magnets, and the reason why the design of $4.0 \mathrm{~mm}$ in $w_{a}$ has been chosen is that its torque is highest in the previous investigation given in Fig. 3. After current goes up more than $8 \mathrm{~A}$, the average torque of the permanent-magnetassisted SRM becomes lower than no-permanent-magnet design since there is more saturation in the stator pole of the permanent-magnet-assisted SRM due to the removal of steel by making two pockets in each stator pole.

In an SRM, electromagnetic torque is proportional to the rate of change of inductance as expressed below.

$$
\tau(\theta, \mathrm{i})=\frac{1}{2} i(\theta)^{2} \frac{d L(\theta, i)}{d \theta}
$$

where $\tau, i, L$, and $\theta$ are the electromagnetic torque, phase current, inductance, and rotor position, respectively.

Considering that average torque in Fig. 4 is estimated under the condition of constant current, torque difference between the permanent-magnet-assisted and no-permanentmagnet SRMs is dependent only on inductance. The inductance of the no-permanent-magnet SRM is determined by following.

$$
L_{1}(\theta, i)=\frac{N \cdot \varnothing_{m, 1}}{i(\theta)}=\frac{N}{i(\theta)} \varnothing_{c o i l, 1}
$$

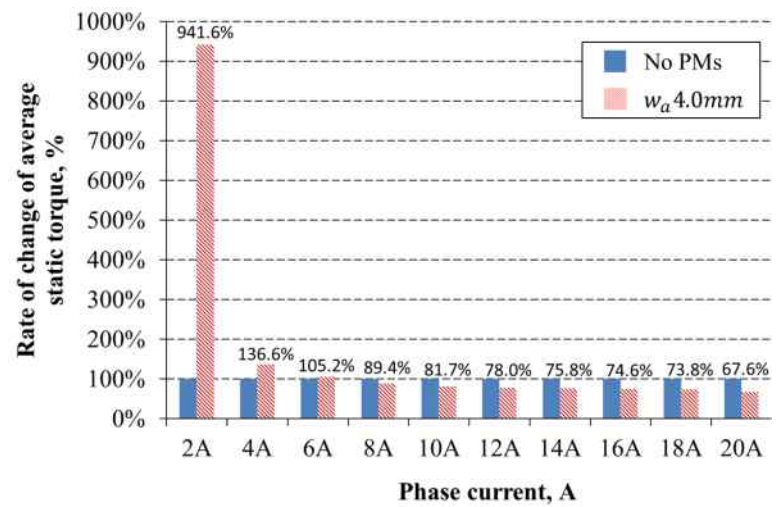

Fig. 4. Average static torque in the permanent-magnetassisted SRM compared to the case of no permanent magnets by varying phase current

Inductance in case of the proposed SRM is expressed as

$$
L_{2}(\theta, i)=\frac{N \cdot \varnothing_{m, 2}}{i(\theta)}=\frac{N}{i(\theta)}\left(\varnothing_{c o i l, 2}+\varnothing_{p m}\right)
$$

where $\mathrm{N}, \varnothing_{\text {coil }, 1}, \varnothing_{\text {coil }, 2}$, and $\varnothing_{p m}$ are the number of turns per pole, the flux of windings in the no-permanentmagnet SRM, that of windings in the permanent-magnetassisted SRM, and that of permanent magnets in the permanent-magnet-assisted SRM, respectively.

In Fig. 5, there is the comparison of inductance profiles at $8 \mathrm{~A}$ during one period in the permanent-magnet-assisted SRM versus the no-permanent-magnet SRM. Since the slope of inductance in the permanent-magnet-assisted SRM is less steep, the corresponding torque has to be reduced by $10.6 \%$ compared to the no-permanent-magnet case as given in Fig. 4. Even though the flux of permanent magnets $\left(\varnothing_{p m}\right)$ is added to that of windings $\left(\varnothing_{c o i l, 2}\right)$ in the proposed SRM, the total amount of flux $\left(\varnothing_{p m}+\varnothing_{c o i l, 2}\right)$ deteriorates gradually as phase current increases. This behavior in the permanent-magnet-assisted SRM comes from the magnetic saturation of silicon steel due to the inevitable addition of pockets for permanent magnets in each stator pole. As a result, due to smaller reluctance in

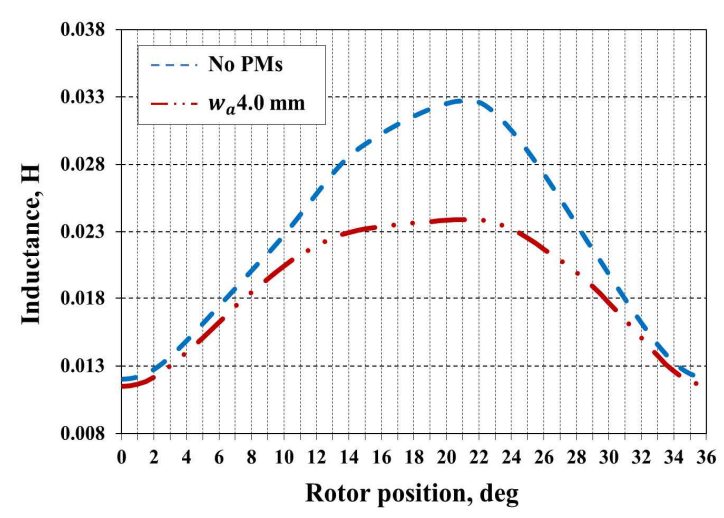

Fig. 5. Inductance of the permanent-magnet-assisted and no-permanent-magnet SRMs at 8A 
the stator pole of the permanent-magnet-assisted SRM, the flux of windings $\left(\varnothing_{\text {coil, } 2}\right)$ becomes less than that of windings in case of no permanent magnets $\left(\varnothing_{\text {coil }, 1}\right)$, and such a deviation in flux from the no-permanent-magnet SRM gets worse as phase current goes up.

\subsection{Design modification for better reluctance}

In order to improve the reluctance of stator excitation poles in the previous permanent-magnet-assisted SRM, another design parameter, the width of a stator excitation pole $\left(w_{c}\right)$, is applied as illustrated in Fig. 6, and its value is

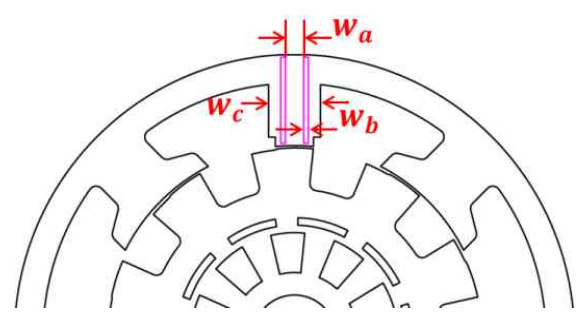

Fig. 6. Another design parameter for improving reluctance: the width of a stator excitation pole $\left(w_{c}\right)$

Table 3. Change of width of a stator excitation pole

\begin{tabular}{l|l|l|l}
\hline$w_{a}$ & $\mathrm{~mm}$ & \multicolumn{2}{|c}{4.0} \\
\hline$w_{b}$ & $\mathrm{~mm}$ & \multicolumn{2}{|c}{1.0} \\
\hline$w_{c}$ & $\mathrm{~mm}$ & 9.26 & \multicolumn{2}{c}{11.26} \\
\hline
\end{tabular}

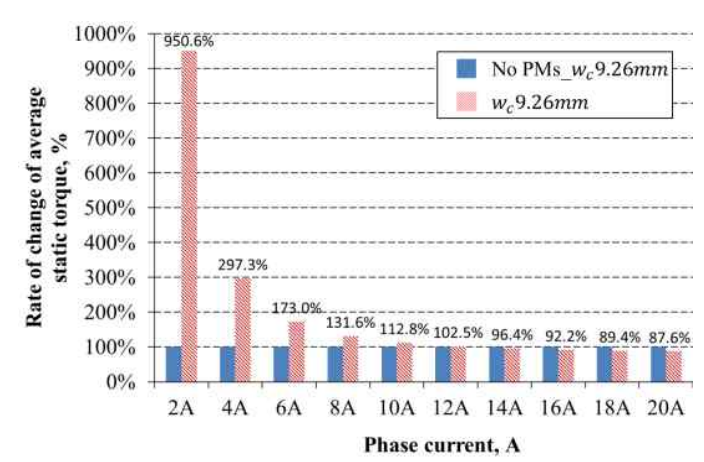

(a)

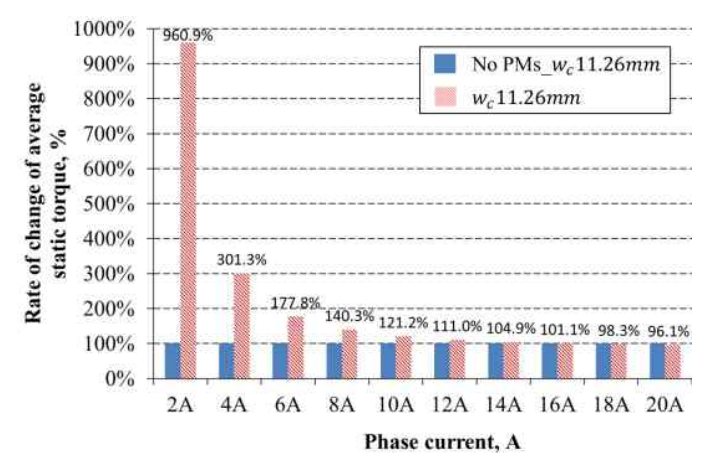

(b)

Fig. 7. Average static torque in the permanent-magnetassisted SRM compared to the case of no permanent magnets by varying the width of a stator excitation pole $\left(w_{c}\right)$, (a) $w_{c}=9.26 \mathrm{~mm}$, (b) $w_{c}=11.26 \mathrm{~mm}$ modified in two steps $\left(9.26 \mathrm{~mm}\right.$ and $11.26 \mathrm{~mm}$ in $\left.w_{c}\right)$ as given in Table 3 . In case of $9.26 \mathrm{~mm}$ in $w_{c}$, the average torque of the permanent-magnet-assisted SRM is improved until $12 \mathrm{~A}$ as shown in Fig. 7(a), and it is noted that thicker width leads to more improvement in average torque compared to no-permanent-magnet case as shown in Fig. 7(b).

\subsection{Increase of copper area}

Although the increase of width of a stator excitation pole $\left(w_{c}\right)$ enables its corresponding reluctance to go down for better performance, the width enlargement causes the reduction of copper area at the same time. Consequently, the width of a common pole $\left(w_{d}\right)$ in Fig. 8 needs to be modified in order to obtain enough space for excitation coils without deteriorating machine performance, and the range of its modification is given in Table 4.

In this case, other design factors such as space between two adjacent permanent magnets $\left(w_{a}\right)$, the thickness of each permanent magnet $\left(w_{b}\right)$, and the width of a stator excitation pole $\left(w_{c}\right)$ are fixed in a constant value as given in Table $\mathrm{V}$ since the influence of $w_{d}$ on torque is a focus in

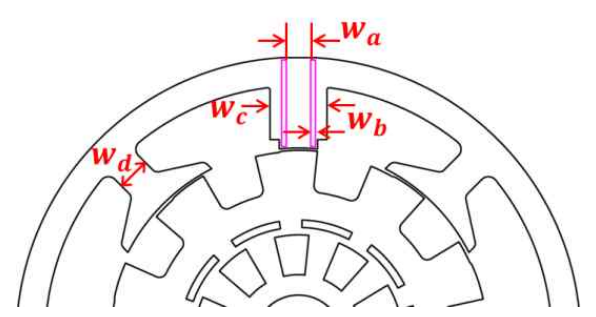

Fig. 8. Last design parameter for enlarging copper area: the width of a common pole $\left(w_{d}\right)$

Table 4. Change of width of a common pole

\begin{tabular}{|c|c|c|c|c|}
\hline$w_{a}$ & $\mathrm{~mm}$ & \multicolumn{3}{|c|}{4.0} \\
\hline$w_{b}$ & $\mathrm{~mm}$ & \multicolumn{3}{|c|}{1.0} \\
\hline$w_{c}$ & $\mathrm{~mm}$ & \multicolumn{3}{|c|}{11.26} \\
\hline$w_{d}$ & $\mathrm{~mm}$ & 5.2 & 6.2 & 7.2 \\
\hline
\end{tabular}

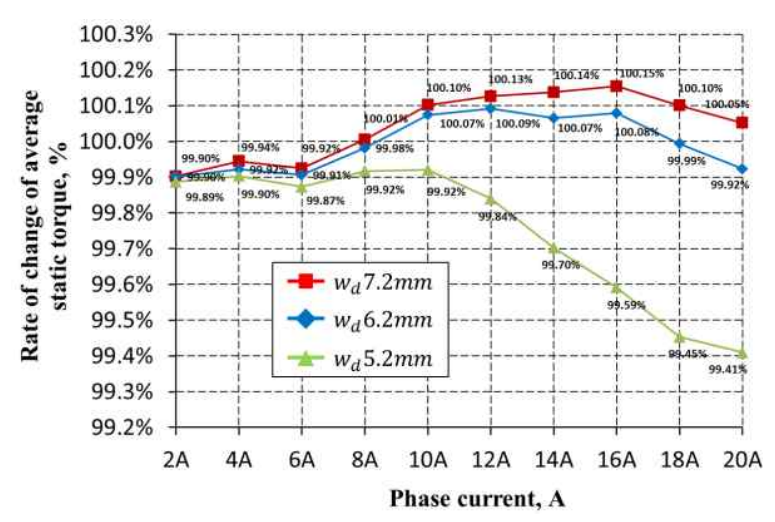

Fig. 9. Average static torque in the permanent-magnetassisted SRM by varying the width of a common pole $\left(w_{d}\right)$ 
this investigation. Compared to the copper area of the reference design, the copper area of width of $5.2 \mathrm{~mm}$, $6.2 \mathrm{~mm}$, and $7.2 \mathrm{~mm}$ are $104.3 \%, 103.2 \%$, and $102.3 \%$, respectively.

Fig. 9 shows the comparison of average static torque in the permanent-magnet-assisted SRM in changing the width of common poles from $7.2 \mathrm{~mm}$ down to $5.2 \mathrm{~mm}$. Both 7.2 $\mathrm{mm}$ and $6.2 \mathrm{~mm}$ cases have a very similar torque characteristic with approximately $0.1 \%$ maximum deviation each other, but there is approximately $0.6 \%$ drop in average torque at $20 \mathrm{~A}$ in case of $5.2 \mathrm{~mm}$ compared to $7.2 \mathrm{~mm}$ design because of longer flux paths in the width of $5.2 \mathrm{~mm}$ leading to higher reluctance.

\subsection{Thickness of a permanent magnet}

Fig. 10 shows the average static torque of sole winding excitation versus permanent magnets in terms of percentage with respect to phase current under the condition of $7.2 \mathrm{~mm}$ in $w_{d}$ and $1.0 \mathrm{~mm}$ in $w_{b}$. It is assumed that permanent magnets' excitation is constant all the time during normal operation, but the strength of coil excitation is significantly dependent on the level of phase current. The portion of torque generated only by coils gets higher as phase current rises, but the situation of permanent magnets is the opposite as illustrated in Fig. 10. At low currents up to $6 \mathrm{~A}$, the ratio of torque of permanent magnets is greater than coil excitation, but torque produced by coils starts being dominated at more than $8 \mathrm{~A}$ due to gradual boost in the magneto-motive force of coils.

Fig. 11 shows the comparison of average torque in five design modifications regarding permanent magnets' thickness $\left(w_{b}\right)$ ranging from $0.6 \mathrm{~mm}$ to $1.4 \mathrm{~mm}$ in $0.2 \mathrm{~mm}$ increments under the condition that the thickness of $1.0 \mathrm{~mm}$ is considered as a base in $100 \%$ at all the levels of phase current. In this case, space between two adjacent permanent magnets $\left(w_{a}\right)$ has to be revised according to the variation of permanent magnets' thickness $\left(w_{b}\right)$ since the width of a stator excitation pole $\left(w_{c}\right)$ is fixed in $11.26 \mathrm{~mm}$, and the dimension of four design parameters are detailed in

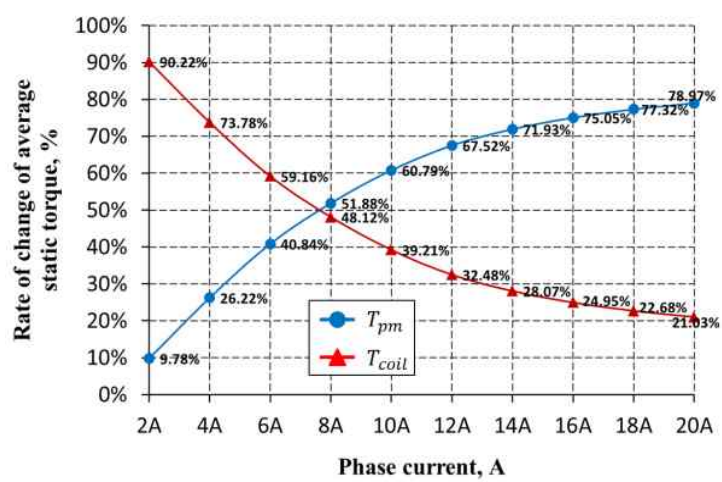

Fig. 10. Average static torque of sole winding excitation versus permanent magnets' fixed excitation with respect to phase current

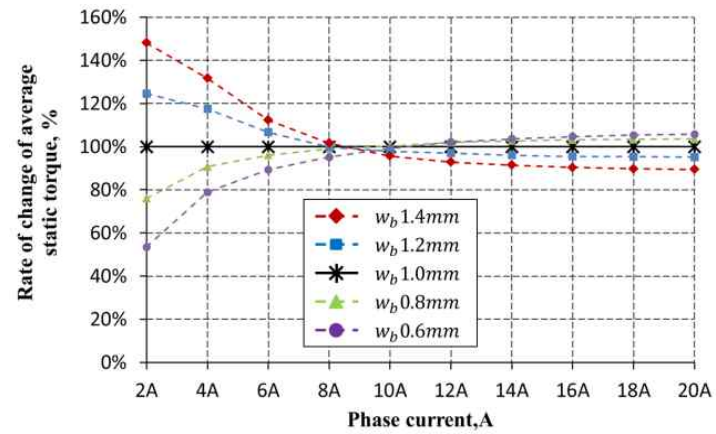

Fig. 11. Average static torque in the permanent-magnetassisted SRM by varying the width of a permanent magnet $\left(w_{b}\right)$

Table 5. Change of width of a permanent magnet

\begin{tabular}{c|c|c|c|c|c|c}
\hline$w_{a}$ & $\mathrm{~mm}$ & 3.2 & 3.6 & 4.0 & 4.4 & 4.8 \\
\hline$w_{b}$ & $\mathrm{~mm}$ & 1.4 & 1.2 & 1.0 & 0.8 & 0.6 \\
\hline$w_{c}$ & $\mathrm{~mm}$ & \multicolumn{5}{|c}{11.26} \\
\hline$w_{d}$ & $\mathrm{~mm}$ & \multicolumn{7}{|c}{7.2} \\
\hline
\end{tabular}

Table 5.

As the thickness of permanent magnets is increased in Fig. 11, the corresponding average torque becomes higher until the phase current of $8 \mathrm{~A}$ compared to the reference design having $1.0 \mathrm{~mm}$ in thickness, but just after this moment, torque generated in the design of interest deteriorates due to more saturation in steel compared to the reference design. Two other modifications in thickness such as $0.6 \mathrm{~mm}$ and $0.8 \mathrm{~mm}$ are the opposite to the previous case, these two designs have more torque than the thickness of $1.0 \mathrm{~mm}$ after $10 \mathrm{~A}$ because there is more space between two adjacent permanent magnets $\left(w_{a}\right)$ in the designs leading to lower reluctance in their excitation poles.

Dynamic performance in the design of $0.6 \mathrm{~mm}$ permanent magnets in thickness has been carried out, and the result of simulation is summarized and compared to $1.0 \mathrm{~mm}$ and $1.4 \mathrm{~mm}$ permanent magnets as given in Table 6 . Also, current and torque waveforms in the three designs are compared in Fig. 12. As mentioned before, the thickness of $0.6 \mathrm{~mm}$ in permanent magnets has better characteristics in the initial build-up of current and positive torque production in minimum and maximum inductances,

Table 6. Summary of the predicted performance at 3,000 RPM

\begin{tabular}{c|c|c|c}
\hline Dimension & \multicolumn{3}{|c}{ PM-assisted SRM } \\
\hline \hline Thickness of the magnet $(\mathrm{mm})$ & 0.6 & 1.0 & 1.4 \\
\hline No. of turns per pole & 133 & 141 & 139 \\
\hline Phase current (A,rms) & 7.117 & 6.908 & 7.897 \\
\hline Speed (rpm) & 3,000 & 3,000 & 3,000 \\
\hline Torque $(\mathrm{Nm})$ & 4.636 & 4.624 & 4.612 \\
\hline Copper loss (W) & 92.8 & 97.4 & 125.5 \\
\hline Core loss (W) & 48.8 & 55.7 & 62.2 \\
\hline Output power (W) & 1456.5 & 1452.5 & 1449.0 \\
\hline Efficiency & $91.1 \%$ & $90.5 \%$ & $88.5 \%$ \\
\hline
\end{tabular}




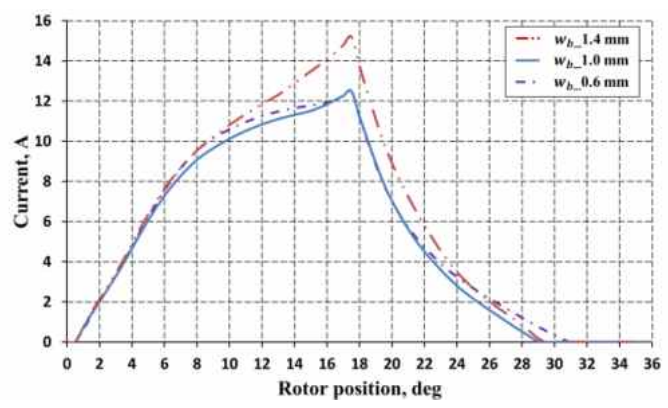

(a)

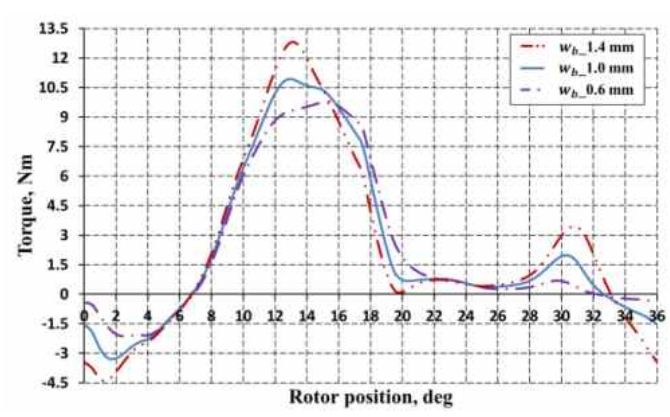

(b)

Fig. 12. Dynamic performance Estimation with singlepulse operation at 3,000rpm: (a) phase current; (b) torque

respectively. In Fig. 12(b), the design of $0.6 \mathrm{~mm}$ thickness has the lowest negative torque even though its current is almost similar to the other two designs in the region of startup, and there is the smallest copper loss of $92.8 \mathrm{~W}$ in the design of $0.6 \mathrm{~mm}$ because of its better positive torque generation compared to the designs of $1.0 \mathrm{~mm}$ and $1.6 \mathrm{~mm}$. Also, realizing that the $0.6 \mathrm{~mm}$ lamination has lower saturation around stator excitation poles, its core loss becomes lowest in $48.8 \mathrm{~W}$ among the three machines. As a result, in the thickness of $0.6 \mathrm{~mm}$ in permanent magnets, there is $0.6 \%$ and $2.6 \%$ deviation in efficiency from $1.0 \mathrm{~mm}$ and $1.6 \mathrm{~mm}$ designs, respectively.

\section{Comparison between No-Permanent-Magnet and Permanent-Magnet-Assisted SRMs}

In this section, a comparison between no-permanentmagnet 8/10 SRM and the proposed permanent-magnet assisted SRM is conducted. Several key criteria are given to design the two machines, and they are detailed as following.

- The same silicon steel is used for stator and rotor laminations

- The external stator and shaft are the same

- Stack length are the same in both SRMs

- The back iron thickness is equal

- Asymmetric rotor pole faces are utilized in the design of the two SRMs to help with self-starting and continuous
Table 7. Dimensions and weights in no-permanent-magnet and permanent-magnet-assisted SRMs

\begin{tabular}{c|c|c}
\hline Dimension & no-PM SRM & PM-assisted SRM \\
\hline Stator outer diameter $(\mathrm{mm})$ & 121.52 & 121.52 \\
\hline Stator inner diameter $(\mathrm{mm})$ & 82.39 & 82.39 \\
\hline Excitation pole arc $(\mathrm{deg})$ & 11.5 & 11.5 \\
\hline Common pole arc $(\mathrm{deg})$ & 36 & 36 \\
\hline \hline Rotor outer diameter $(\mathrm{mm})$ & 81.39 & 81.39 \\
\hline Rotor inner diameter $(\mathrm{mm})$ & 63.68 & 63.68 \\
\hline Rotor pole arc $(\mathrm{deg})$ & 19.0 & 19.0 \\
\hline \hline Maximum air gap $(\mathrm{mm})$ & 0.5 & 0.5 \\
\hline Stack length $(\mathrm{mm})$ & 70.0 & 70.0 \\
\hline Winding turns per pole & 111 & 133 \\
\hline Slot fill factor & $70.0 \%$ & $70.0 \%$ \\
\hline \hline Stator iron mass $(\mathrm{g})$ & 1983.1 & 1911.1 \\
\hline Rotor iron mass $(\mathrm{g})$ & 1775.5 & 1775.5 \\
\hline Winding mass $(\mathrm{g})$ & 1222.0 & 4911.1 \\
\hline Total machine mass $(\mathrm{g})$ & 4980.6 & \\
\hline
\end{tabular}

torque production

- Maximum radial air gap length between stator and rotor poles is set to $0.5 \mathrm{~mm}$

- Operating speed and rated torque is 3,000rpm and 4.6Nm, respectively

Critical dimensions and weights in both SRMs for comparison are summarized in Table 7.

\subsection{Static performance comparison}

From Eq. (1), torque is proportional to the square of phase current and the rate of change of inductance with respect to rotor position. Figs. 13(a) and 13(b) give inductance profiles of two $8 / 10$ SRMs without permanent magnets and with permanent magnets, respectively. The inductances are plotted at various constant phase currents, and in this case, torque is solely dependent on the slope of inductance.

It is clear that the insertion of two thin permanent magnets into each stator excitation pole improves the addition of flux leading to the increase of inductance slope in the permanent-magnet-assisted SRM. As a result, this machine is able to end up with more torque generation compared to the $8 / 10 \mathrm{SRM}$ with no permanent magnets.

Fig. 14(a) and 14(b) present static torque profiles in the two 8/10 SRMs for both phases at five different levels of phase current. It is noted that the permanentmagnet-assisted SRM has higher average torque than no-permanent-magnet design due to the insertion of permanent magnets. The average torque of the permanentmagnet-assisted SRM is higher by $147 \%$ and $17 \%$ at $4 \mathrm{~A}$ and $20 \mathrm{~A}$, respectively, and as a result, the effect of permanent magnets becomes less as phase current goes up because of magnetic saturation in steel. The improvement of static torque in the permanent-magnet-assisted SRM needs to be quantitatively evaluated in efficiency during dynamic operation. 


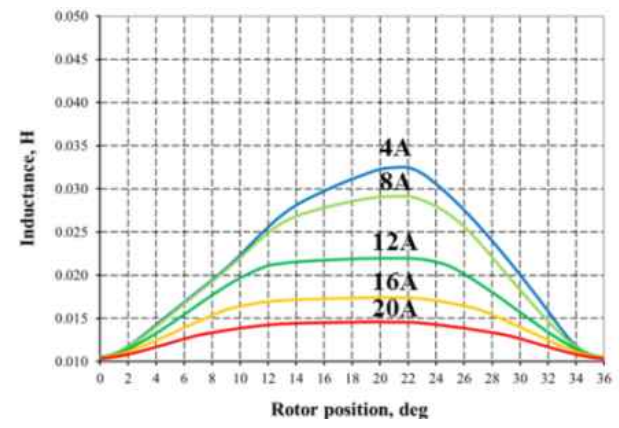

(a)

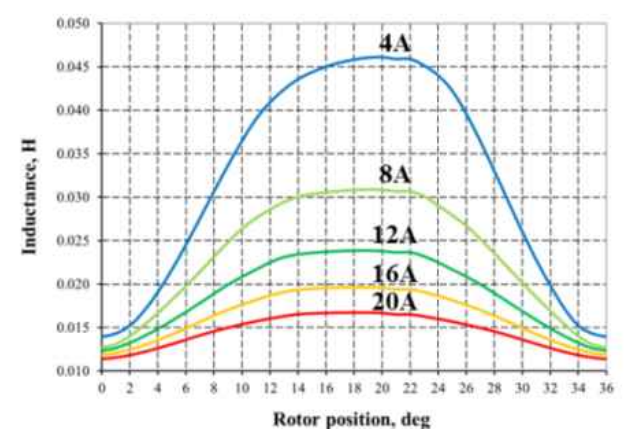

(b)

Fig. 13. Inductance profiles of two $8 / 10$ SRMs at various currents: (a) no-permanent-magnet SRM; (b) permanent-magnet-assisted SRM

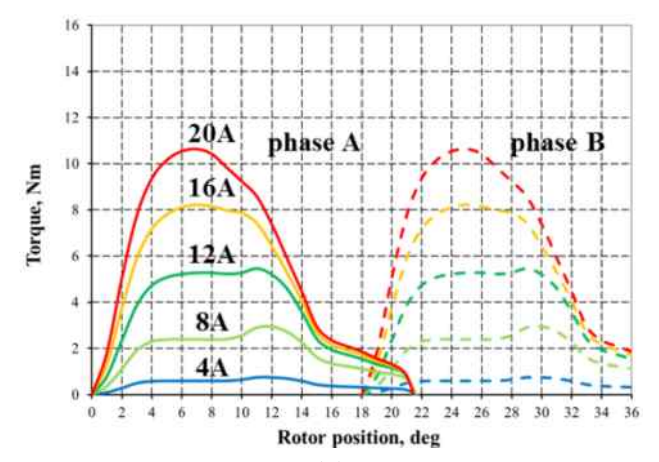

(a)

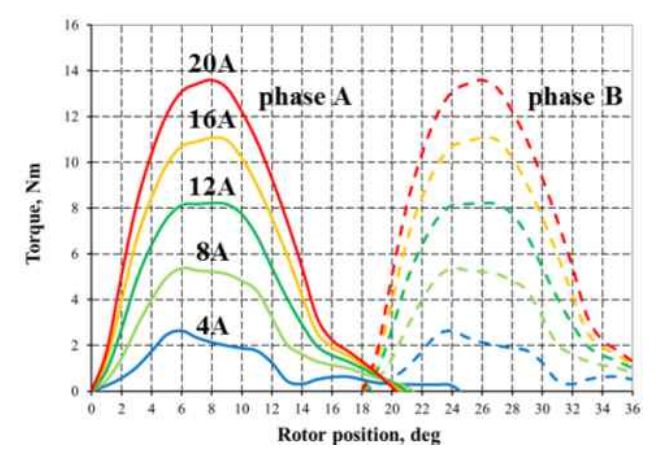

(b)

Fig. 14. Torque profiles of two $8 / 10$ SRMs at various currents: (a) no-permanent-magnet SRM; (b) permanent-magnet-assisted SRM

\subsection{Dynamic performance comparison}

The dynamic simulation of both SRMs is conducted under single pulse operation at $3000 \mathrm{rpm}$ using the same switching angles of 6.2 and 17.2 degrees in advance and dwell angles, respectively, and the result of simulation is summarized in Table 8. In the permanent-magnet-assisted SRM, there is a drop of $70.6 \mathrm{~W}$ and $4.1 \mathrm{~W}$ in copper and core losses, respectively. Therefore, the permanent-magnetassisted SRM has an increase of $4.0 \%$ in the predicted efficiency over no-permanent-magnet SRM.

In Fig. 15, phase current waveforms are compared at 4.6 $\mathrm{Nm}$ of rated torque. Since no-permanent-magnet SRM has to create the same rated torque without permanent magnets, its phase current shows a sharp increase up to a peak of approximately $22 \mathrm{~A}$ as shown in Fig. 15(a). On the other

Table 8. Summary of dynamic performance

\begin{tabular}{|c|c|c|c|c|}
\hline & \multicolumn{2}{|c|}{ no-PM SRM } & \multicolumn{2}{|c|}{ PM -assisted SRM } \\
\hline PM thickness (mm) & \multicolumn{2}{|c|}{ - } & \multicolumn{2}{|c|}{0.6} \\
\hline$\#$ of turns per pole & \multicolumn{2}{|c|}{111} & \multicolumn{2}{|c|}{133} \\
\hline Speed (rpm) & \multicolumn{2}{|c|}{3,000} & \multicolumn{2}{|c|}{3,000} \\
\hline DC link voltage (Vdc) & 310 & 300 & 310 & 300 \\
\hline Phase current (Arms) & 10.03 & 9.34 & 7.12 & 6.99 \\
\hline Torque $(\mathrm{Nm})$ & 4.640 & 4.320 & 4.636 & 4.508 \\
\hline Copper loss (W) & 163.4 & 141.8 & 92.8 & 89.6 \\
\hline Core loss (W) & 52.9 & 50.7 & 48.8 & 48.0 \\
\hline Output power (W) & 1458 & 1357 & 1457 & 1416 \\
\hline Efficiency (\%) & 87.1 & 87.6 & 91.1 & 91.1 \\
\hline
\end{tabular}

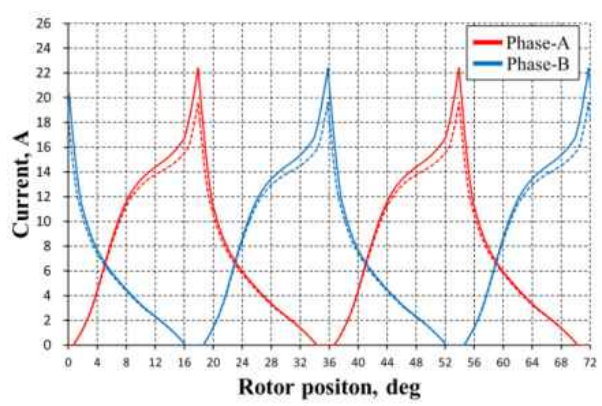

(a)

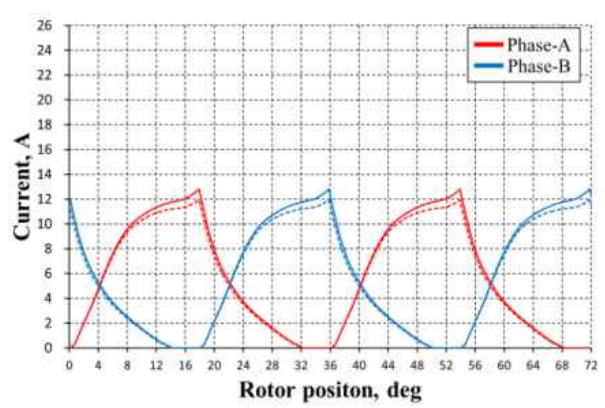

(b)

Fig. 15. Phase current in dynamic performance simulation with single pulse operation: (a) no-permanentmagnet SRM; (b) permanent-magnet-assisted SRM (solid line: $310 \mathrm{Vdc}$, dotted line: $300 \mathrm{Vdc}$ ) 


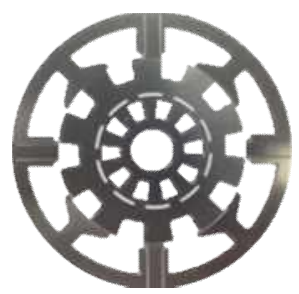

(a)

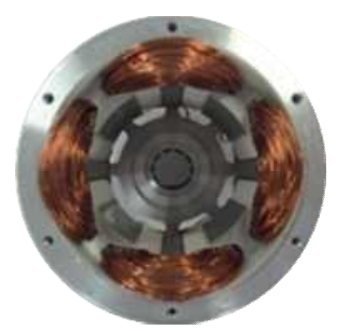

(c)

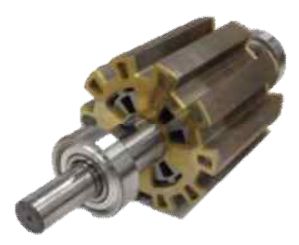

(b)

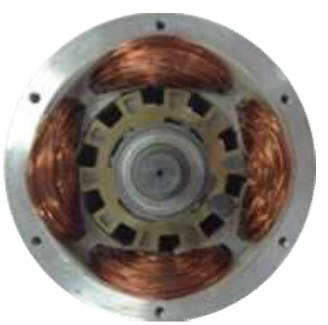

(d)
Fig. 16. Photographs of the first prototype of permanentmagnet-assisted SRM: (a) stator and rotor laminations; (b) rotor assembly; (c) stator with windings; (d) stator-rotor assembly

hand, as shown in Fig. 15(b), there is a significant drop of phase current by approximately 3 Arms in the permanentmagnet-assisted SRM due to the aid of permanent magnets. This is because the addition of permanent magnets gives rise to an increase in inductance slop leading to torque enhancement as shown in Figs. 13 and 14. The first prototype of a permanent-magnet-assisted SRM having the thickness of $0.6 \mathrm{~mm}$ in permanent magnets is given in Fig. 16 and its stator and rotor laminations, rotor assembly, stator with windings, and stator-rotor assembly are shown in Fig. 16(a), (b), (c), and (d), respectively.

\subsection{Experimental verification}

The experimental set up and driving converter of a prototype permanent-magnet-assisted SRM are shown in Fig. 17. Using an asymmetric topology, the motor test has been conducted with a single-pulse operation at 3,000 rpm, but due to the limit of the testing system in power, the efficiency of the SRM has been measured at approximately

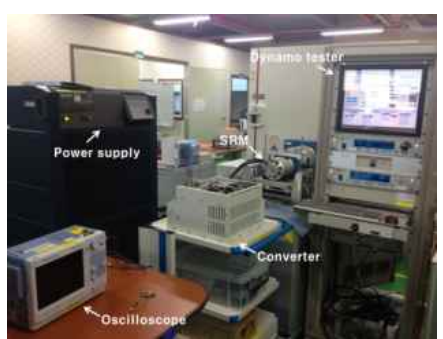

(a)

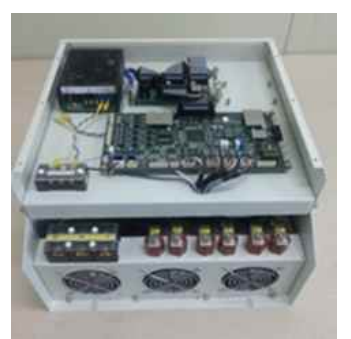

(b)
Fig. 17. Experimental set up with the first prototype of permanent-magnet-assisted SRM: (a) testing installation; (b) converter drive

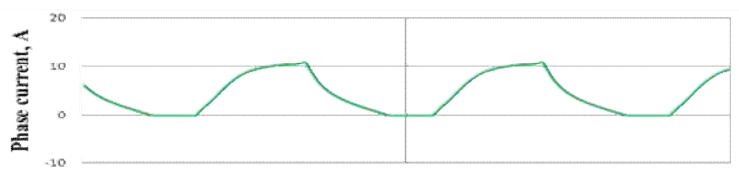

(a)

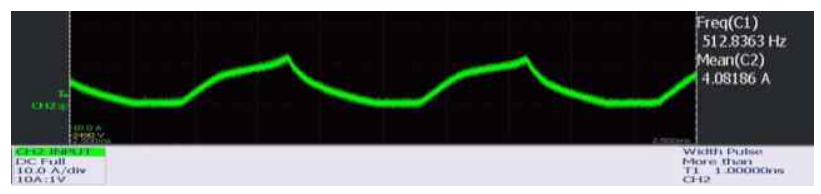

(b)

Fig. 18. Phase current of the first prototype of permanentmagnet-assisted SRM at 3,000rpm with a singlepulse operation: (a) dynamic simulation; (b) laboratory testing (scale: $10 \mathrm{~A} / \mathrm{div}$ )

$1 \mathrm{~kW}$. Phase currents from dynamic simulation and laboratory testing are compared in Fig. 18 under the same condition of operation. It is seen that the two waveforms matches well, and the measured efficiency is $87.1 \%$ and there is $1.8 \%$ deviation compared to the estimated efficiency of $88.9 \%$

\section{Conclusion}

A permanent-magnet-assisted SRM is proposed for efficiency improvement, and its concept, design, and analysis has been presented. Two thin permanent magnets are inserted into every stator excitation pole in such a way that the permanent magnets are magnetized according to the polarity of windings in each stator pole. Three key design parameters such as the thickness of permanent magnets, space between two adjacent permanent magnets, and the width of stator excitation poles are determined during a design procedure. The insertion of permanent magnets into excitation poles enables the machine to be significantly improved in the initial build-up of current and positive torque production as well. It can be concluded that the thickness of permanent magnets is considered as the most critical factor in efficiency during step-by-step design processes. The thickness of $0.6 \mathrm{~mm}$ in permanent magnets has $0.6 \%$ and $2.6 \%$ boost in efficiency over $1.0 \mathrm{~mm}$ and $1.6 \mathrm{~mm}$ thickness, respectively. The benefit of the proposed permanent-magnet-assisted structure has been verified analytically by a comparison with no-permanentmagnet SRM in terms of static torque comparison along with dynamic performance estimation. The proposed permanent-magnet-assisted SRM is higher than nopermanent-magnet-assisted SRM by $4.0 \%$ in efficiency under the condition of the same output power. The first prototype has been built up, and its stator and rotor laminations including its physical assembly are given in 
this paper. Finally, the proposed motor has been experimentally verified by giving the result of laboratory testing compared to that of estimation.

\section{References}

[1] Jin Hur, Jin-Wook Reu, Byeong-Woo Kim, and GyuHong Kang, "Vibration Reduction of IPM-Type BLDC Motor Using Negative Third Harmonic Elimination Method of Air-Gap Flux Density," IEEE Trans. Ind. Appl., vol. 47, no. 3, pp. 1300-1309, May. / June. 2011.

[2] R. Krishnan, Switched Reluctance Motor Drives. Boca Raton, FL: CRC Press, 2003.

[3] Ming Cheng, K.T. Chau, and C.C. Chan, "Design and Analysis of a New Doubly Salient Permanent Magnet Motor," IEEE Trans. Magn., vol. 37, no. 3, pp. 30123020, Jul. 2001.

[4] Y. Liao, F. Liang and T. A. Lipo, "A novel permanent magnet machine with doubly saliency structure", Proc. IEEE IAS Annual Conf., 1992, pp. 308-314.

[5] R.P. Deodhar, S. Andersson, I. Boldea, et al "The flux-reversal machine: a new blushless doubly-salient permanent-magnet machine," Proc. IEEE IAS Annual Conf., 1996, pp. 786-793.

[6] E. Hoang, A.H. Ben-Ahmed, J. Lucidarme, "Switching flux permanent magnet poly phased machines," European Conf. Power Electronic and Applications, 1997, vol. 3, pp. 903-908.

[7] Cheewoo Lee and R. Krishnan, "New Designs of a Two-Phase E-Core Switched Reluctance Machine by Optimizing the Magnetic Structure for a Specific Application: Concept, Design, and Analysis," IEEE Trans. Ind. Appl., vol. 45, no. 5, pp. 1804-1814, Sep./ Oct. 2009.

[8] Hongsik Hwang, Jin Hur and Cheewoo Lee, "Novel permanent-magnet-assisted switched reluctance motor (I): Concept, design, and analysis," 2013 International Conf. Electrical Machines and Systems (ICEMS), pp. 602-608, Oct. 2013.

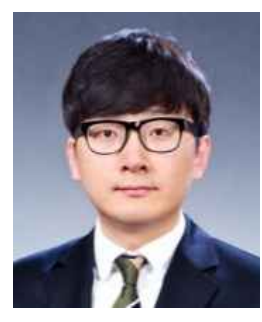

Hongsik Hwang $\mathrm{He}$ received B.S degree in electrical engineering from Kyungsung University, Pusan, Korea, in 2013. He is currently working toward M.S degree in electronics and electrical engineering from Pusan National University, Pusan, Korea. His research interest includes the design and control

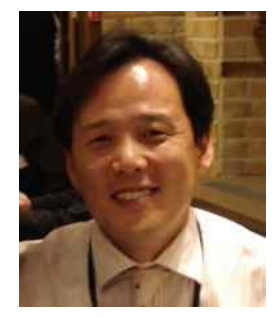

Jin Hur (S'93-M'98-SM'03) received his Ph.D. in Electrical Engineering from Hanyang University, Seoul, Korea, in 1999. From 1999 to 2000, he was with the Department of Electric Engineering, Texas A\&M University, College Station, TX, as a Postdoctoral Research Associate. From 2000 to 2001, he was a Research Professor of Electrical Engineering for BK21 projects at Hanyang University. From 2002 to 2007, he was a Director of Intelligent Mechatronics Research Center, Korea Electronics Technology Institute (KETI), Puchon, Korea, where he worked on the development of special electric machines and systems. Since 2008, he has been an Associate Professor, School of Electric Engineering, University of Ulsan, Ulsan, Korea. He is the author of over 140 publications on electric machine design, analysis and control, and power electronics. He has 1 granted pending US patent and 20 granted pending Korean patents. His current research interests include high-performance electrical machines, modeling, drives, new concept actuators for special purposes and numerical analysis of electromagnetic fields. Dr. Hur is working as an Associate Editor for IEEE Transaction on Power.

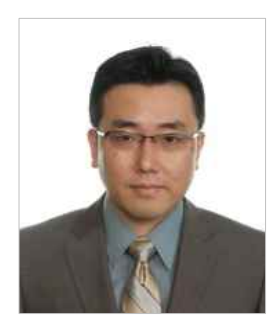

Cheewoo Lee was born in Pusan, Korea, in 1972. He received the B.S. and M.S. degrees in electrical engineering from Pusan National University, Pusan, South Korea, in 1996 and 1998, respectively. He received Ph.D in electrical and computer engineering at Virginia Polytechnic Institute and State University, Blacksburg, USA. He is an assistant professor of electrical engineering at Pusan National University. His research interests include the design of electric machines and their optimal operation. 